\title{
WAR WITHOUT WEAPONS - CONSTITUTION OF HEALTHY AND PATHOLOGICAL PHENOTYPES ASSOCIATED WITH POLYMORPHISMS IN GENES INVOLVED IN THE MAINTENANCE OF GENOME INTEGRITY
}

\author{
Omoboye Adebola Oluwaseun and Hilal S. Khalil \\ University of Abertay Dundee, School of Contemporary Sciences, Cancer Systems Biology, Scotland, UK \\ Correspondence to: Hilal S. Khalil \\ E-mail: H.Khalil@abertay.ac.uk
}

\begin{abstract}
Capacity to repair DNA damage may vary significantly between individuals coming out as healthy on routine physical and laboratory examinations. This variance does not generally cause distress or disease unless in case that specific triggers are present, but, taken together with other factors, may increase the risk for certain types of cancer or may modulate the outcome of anticancer therapies. Carriership of certain polymorphic variants in DNA repair genes may also modify the course of the normal process of aging. The present paper reviews the role of some of the common polymorphisms in DNA repair genes and in genes involved in the maintenance of genomic integrity; and their association, separately or in combination, with the 'healthy' phenotype and with certain diseases and conditions related to exposure to increased levels of oxidative damage.
\end{abstract}

Biotechnol. \& Biotechnol. Eq. 2012, 26(4), 3073-3078

Keywords: capacity for DNA repair, DNA polymorphisms, p53, HMGA1

\section{Setting up the individual capacity for managing genotoxic damage}

An unjust peace is better than a just war.

Marcus Tullius Cicero (106 BC - 43 BC)

DNA is an extraordinary molecule. A well-beaten cliché, of course, but, at the same time, a succinct summary of the complicated and often paradoxical history of the discoveries about the various properties of DNA during the course of the past century. After it has been demonstrated that the presence of DNA in the living cells amounts to much more than a mere support or ballast function, it has been proposed that DNA has been selected as the ultimate carrier of genetic information in the course of evolution because of its stability and resistance to alterations. Later it became clear, however, that proneness to modification is an innate property of DNA-mediated inheritance and functions as a major drive of evolution. Repair of DNA, therefore, became a focus of research only in the last couple of decades, and, as it has always been in the history of DNA research, there were numerous turning points. For instance, genes and proteins participating in DNA repair in humans were discovered in the course of studying the associated human conditions (16), and it was proposed, respectively, that defects in the coding regions of most of the essential DNA repair genes would lead almost invariably to severe, early-onset disease. Examples to support this notion were numerous, and the case report of Fujiwara et al. in 1981 (23) and the follow-up reports by Itoh et al. in 1996 (33) and Horibata et al. in 2004 (30) that homozygous carriership of null alleles of the ERCC6 (CSB) gene may only result in photosensitivity instead of full-blown Cockayne syndrome were hotly disputed, checked and rechecked by sequencing studies. This resulted in the emergence of the novel term "UVsensitivity syndromes" and the realization that allelic disorders of DNA repair may belong to the extremes of the clinical spectrum, some presenting with very severe phenotype, other subclinical or virtually latent except in the presence of specific triggers. The breaking point in the views about the 'permissible' degree of variation in DNA repair genes was, however, in 1990, when Ara et al. (3) reported that the pro72to-arg (P72R) change in exon 4 of the gene coding for the tumour-suppressor protein $\mathrm{p} 53$ is a polymorphism rather than a mutation. In mid-90-ties, numerous polymorphisms in basic DNA repair genes ( $X P D, E R C C 1, X R C C 1, X R C C 3$, etc.) were identified $(7,65)$. Several of these have been found later to be associated with diminished capacity for repair of DNA damage and, respectively, with increased risk of various cancers and possibly with other age-related diseases $(44,51,60,67)$. In 2000 , the polymorphic insertion of $83 \mathrm{bp}$ in intron 9 of the $X P C$ gene was reported (36). Ever since, the effects of DNA polymorphisms on proficiency of DNA repair and, respectively, on the closely related matter of individual repair capacity has been explored under physiological conditions and in disease. It has been found that the capacity to repair DNA damage may vary significantly between individuals coming out as healthy on routine physical and laboratory examinations. This variance in itself does not generally cause distress or disease, unless under specific conditions or specific type of genotoxic stress (e.g. increased propensity to sunburn in individuals with specific genotypes) $(27,48)$ but, taken together with other factors, may increase the risk for certain types of cancer (e.g. increased risk of lung or colon cancer in smokers or increased risk of melanoma in light-skinned individuals with a history of extensive sun exposure). On the other hand, carriership of polymorphisms in genes coding for proteins involved in 
DNA repair was found to modulate the outcome of anticancer therapies in terms of survival and therapy-related toxicity $(26,66)$, as most anticancer therapies are based on inflicting genotoxic damage on cancer cells so as to reduce their proliferative capacity and/or induce apoptosis. What is more, it has been shown that carriership of polymorphic variants in DNA repair genes may influence the process of aging. Very recently, it has been reported that murine models defective by the nucleotide excision repair genes Erccl and Xpd may exhibit accelerated senescence of the wall of the blood vessels, with resulting vascular stiffness and arterial hypertension at a young age (19).

Information on the role of the non-disease polymorphic variants of genes associated with repair of DNA damage and management of genome integrity has been steadily accumulating for the past 20 years. The present paper reviews the role of some of the common polymorphisms in DNA repair genes and in genes involved in the maintenance of genomic integrity and their association, separately or in combination, with certain diseases and conditions related to exposure to increased levels of oxidative damage.

\section{Polymorphisms in genes encoding products directly responsible for DNA repair and/or induction of apoptosis}

One may know how to gain a victory, and know not how to use it.

Pedro Calderon de la Barca (1600-1681)

Of the numerous genetic polymorphisms that may influence the individual capacity for repair of DNA damage, few are those which are endowed with an information value of their own. Among the latter prominent are the already mentioned P72R polymorphism in the TP53 gene and several single-nucleotide substitutions in the gene coding for the helicase XPD. Their applicability may vary, however, depending on whether they are used alone or in combination with other factors, or the context in which they are being used.

\section{p53}

The responsibility for integrating the signals for presence of genotoxic damage, for quantification of the amount of damage, and taking the decision about the fate of the damaged cell is essentially a prerogative of $\mathrm{p} 53$. Germline mutations affecting regions of the gene encoding domains responsible for the properties of p53 to transactivate its target genes or its retention in the nucleus usually result in Li-Fraumeni syndrome, a cancer-prone phenotype (53). Several polymorphisms in the coding sequence as well as in the introns of the TP53 gene have been identified so far (62).

After assessment of the amount and the scale of DNA damage, p53 may launch one of two basic pathways, one of which is 'repair mode', that is, G1/S cell cycle arrest until DNA damage is repaired; or, alternatively, the programmed cell death routine may be activated. In both cases, cells which have sustained genotoxic DNA damage (or almost any type of damage, for that matter) are specifically dealt with in order to effectively decrease the amount of damage. The means to achieve this, and, respectively, the outcomes may be very different - the damaged DNA may be repaired and the cell may live (and, potentially, divide further) - admittedly with some risk that unrepaired or improperly repaired damage might persist further; or the cell may die by apoptosis (and be promptly replaced by a new cell produced by the stem cell population). Assessment of damage and launching one type of response or another is largely dependent on p53, therefore, it is a prime target for inactivation in cancer cells. Alterations in the gene coding for p53 (loss of allelic copies, inactivating mutations, promoter methylation, etc.) are common in tumours and loss of activity of p53 may be one of the last barriers that a cell already on the way of cancerous transformation must overcome before becoming truly malignant $(45,50)$. Restoration of p53 function and/or increasing the levels of normal isoforms of p53 in cancer cells is one of the therapeutic options in modern anticancer therapy $(39,47)$. It has been shown in murine models, however, that constitutively high levels of the non-cancerous isoforms of p53 are associated with a striking phenotype of premature aging (24). It is believed that the aging is a major anticancer mechanism that p53 deploys in order to ensure that cells at high risk of significant alterations in their DNA are systematically and safely removed from the replicative pool $(10,35,57)$.

Apparently, the levels of p53 as well as its activity must be exquisitely balanced in order for a healthy individual to age at a normal rate and to remain healthy throughout. The properties of 'normal' p53 in regard to its ability to induce cell cycle arrest or apoptosis may not be equivalent. Whether p53 is a stronger transcription activator or a stronger inducer of apoptosis depends on the genotype for the P72R polymorphism in exon 4, with the $\mathrm{R}$ allele conferring pro-apoptotic properties and the $\mathrm{P}$ allele more strongly associated with the ability to induce G1/S cell cycle arrest (69). In young and healthy individuals, the presence of the one or the other genotype does not constitute either advantage or disadvantage, except that individuals with the PP genotype may have a slight reproductive disadvantage compared to RR and PR individuals because of a somewhat higher incidence of early embryo implantation failures (20). The $\mathrm{P}$ allele is more common in the geographical areas near the equator while the $\mathrm{R}$ allele generally becomes more common nearer the poles (64), which is believed by some authors to be related to the dose of environmental genotoxic agents (specifically, UV radiation) regularly received at different latitudes and the presence of other protective factors (14). Carriership of the different allelic forms of p53, especially homozygous carriership, however, may play a role of its own in older individuals and/or individuals affected with different conditions. This role may be complex, as, on the one hand, homozygous carriership of the pro-apototic $R$ allele has been shown to decrease the incidence of cancer in elderly individuals almost twofold (17), while carriership of homozygous $P$ allele has been shown to be associated with an increase in median lifespan compared to $R R$ homozygotes (6). Longevity associated with carriership of different allelic forms 
of p53 seems to have its specific cellular substrates, as it has already been shown that reduced p53 activity in genetically engineered mice is associated with higher counts of circulating hematopoietic progenitor cells in advanced age compared to normal control mice $(5,18)$. It has been demonstrated, however, that individuals with homozygous $\mathrm{R} / \mathrm{R}$ genotypes may have poorer outcomes after incidents of acute ischaemia, which is most likely related to the proneness of damaged $\mathrm{R} / \mathrm{R}$ cells to apoptosis compared to cells with $\mathrm{P} / \mathrm{R}$ and $\mathrm{P} / \mathrm{P}$ genotypes (1, 25). Apparently, the process of physiological aging as well as the process of development of disease may serve as tipping points in the balance between the pro-transactivation and the pro-apoptotic properties of $\mathrm{p} 53$, with consequences dependent on the combined impact of other factors $(35,72)$.

\section{XPD}

XPD is ATP-dependent 5' -3 ' DNA helicase, component of the TFIIH basal transcription factor (68). Since the function of $\mathrm{XPD}$ is indispensable in both basic types of repair by nucleotide excision, mutations in the XPD gene may produce any of the basic NER-deficient phenotypes in humans - xeroderma pigmentosum (XP); XP combined with Cockayne syndrome; and trichothiodystrophy, depending on the site and the type of the mutation (38). Several polymorphic single-nucleotide substitutions in the $X P D$ gene have been identified in exons 6 , $8,10,17,22$, and $23(7,65)$. Two of these polymorphisms Asp312Asn (exon 10) and Lys751Gln (exon 23), are considered common in all populations. Carriership of any of these generally results in higher levels of DNA adducts, suggesting lower capacity for repair of DNA lesions via NER $(31,41)$. Human lymphoblastoid cells carrying the Asn allelic variant have been reported to exhibit diminished apoptotic response to genotoxic challenge (63). Increased risk for various cancers and for development of senile cataract has been found to be associated with carriership of the Asp312Asn and Lys751Gln polymorphisms $(44,51,67,71)$. Also, carriership status of the one or the other allele may play a role in the outcome of different anticancer therapies (see below).

\section{Role of mutations in genes not related directly to DNA repair but associated with maintenance of genome integrity in the constitution of pathological phenotypes}

You cannot simultaneously prevent and prepare for war.

Albert Einstein (1879-1955)

The idea of individual repair capacity as the product of genetic background (carriership of polymorphic alleles of genes involved in DNA repair which is associated with increased or decreased ability for efficient and/or timely repair of everyday DNA damage) and environmental factors (new sources of genotoxic damage or increase in the level of preexisting genotoxic damage) covers and explains most of the known cancer predispositions. It has been repeatedly demonstrated, however, that oxidative damage to cells and tissues is a major pathogenetic mechanism in many seemingly unrelated (that is, non-cancerous) conditions such as insulin resistance, atherosclerosis, Parkinson's and Alzheimer's disease, and possibly others. All these diseases and conditions have a common unifying point though, as they are characterized by a propensity for accelerated aging of certain types of cells and tissues. Also, these diseases and conditions are considered to be diseases typical of advanced age, despite the fact that modern humans live up to several decades longer than men of 150 years ago and therefore the concept of advanced age apparently is up for revision. Indeed, the incidence of cancer is much higher in the group of 65 years and above than in any other age group, but prolonged and/or intensive oxidative stress may not manifest as cancer proneness only. Increased levels of oxidative stress are presently considered to be a characteristic feature of insulin-resistant diabetes and atherosclerosis $(4,22)$, and it has been found in animal models as well as in humans that predispositions to insulin-resistant phenotype may result from heritable variations in genes coding for products participating in certain types of DNA repair (specifically, the Fpg/Nei family of glycosylases which perform the first steps of BER repair of oxidized bases in DNA $(58,73))$ and also from mutations in genes associated with the maintenance of the genome integrity, but not strictly related to DNA repair, such as $\operatorname{HMGA1}(15,21)$. HMGA proteins play a role in the maintenance of the architecture and the dynamics of the chromatin and, respectively, in the regulation of transcription of various genes in non-cancerous and cancer cells $(2,43)$. It has been proposed that homozygocity for certain HMGA1 mutations may result in decreased intrauterine viability in mammal embryos, while carriership of only one mutant allele of HMGA1 may be associated with predisposition for development of insulin resistance $(15,21)$. Recent theories have put forth faulty DNA repair as a major mechanism in the pathogenesis of the insulin resistant phenotypes (metabolic syndrome, diabetes type 2 ) and atherosclerosis $(42,46)$ and it has been proposed that insulin resistance is, in fact, a low-grade premalignant state in which DNA damage is slowly accumulating to a point where it cannot be handled by the repair machinery of the cell, triggering accelerated aging and/or carcinogenesis (54).

It has been demonstrated that the risk for development of insulin resistance may be modulated by carriership of certain genetic polymorphisms in genes coding for products involved in the repair of DNA damage, among which prominent is the already mentioned P72R polymorphism in the TP53 gene. It has been found that carriership of the pro-apoptotic $(R)$ allele of p53 is associated with higher risk of development of diabetes type 2 than in non-carriers $(8,55)$. Mass apoptosis of selected cell populations is a hallmark of the pathogenesis of some of the common severe consequences of uncontrolled hyperglycemia - accelerated vascular aging, retinopathy, neuropathy, etc. It could be hypothesized that the presence of the pro-apoptotic form of p53 in cells which are already under increased levels of genotoxic stress for any reason, may serve well when the organism is young, but not that well as the organism ages, possibly as an expression of the phenomenon of antagonistic pleiotropy (35). More specifically, in case that the underlying hyperglycemic state is poorly managed, the pro-apoptotic p53 may handle the ongoing avalanche of genotoxic damage at young age by routing cells with potential for oncogenic 
transformation to the programmed cell death pathway. As the remaining reserve of stem cells in the tissues of the young adult is fully functional, it promptly produces new cells to replace these that have been removed by apoptosis. Once the stem cell reserve is depleted, however, or its replicative capacity is diminished, as happens as age advances, permanent tissue damage settles in. Thus, the background of increased levels of oxidative stress is provided by the preexisting HMGA1 mutation while carriership of other modulating factors may play a role in the formation of the risk for development of late vascular and possibly retinal pathology associated with insulin resistant phenotypes. The situation may be somewhat different with neurological damage due to oxidative stress, as the possibility for replacement of differentiated neural cells in the adult organism is, at best, limited. It has been demonstrated, however, that some terminally differentiated (and, therefore, non-dividing) cell types, including neurons tend to suppress global genome repair in order to focus all repair machinery to repair actively transcribed genes $(12,32,49)$, therefore it might be the case that checks for genotoxic damage (and, consequently, removal of cells with genomic damage deemed to be serious enough to trigger apoptosis) are less frequent in neural cells, even when they are in conditions of increased levels of genotoxic damage.

\section{Using information about individual repair capacity for design of personalized anticancer therapies}

The best weapon against an enemy is another enemy.

Friedrich Nietzsche (1844-1900)

Modern anticancer strategies involve selection of therapeutic strategies based on the individual characteristics of the patient and design of a personalized therapeutic regimen. Personalization as we know it usually takes into account the type and the basic characteristics of the cancer and then matches the possible therapeutic options to the particular patient in order to determine whether one therapeutic regimen could be more successful and free of adverse reactions than another. A mainstream branch of both classic and modern anticancer therapy is based on genotoxic treatment - that is, introduction of enough genotoxic damage into cancer cells so as to reroute them to the programmed cell death pathway (if it has not been disabled already) or delaying their growth by induction of cell cycle arrest. The amount of genotoxic damage associated with therapy is usually enough to produce adverse effects in healthy tissues. The question is, is a cell with inherent low-than-average capacity for DNA repair (for example, because of carriership of certain genetic polymorphisms) at advantage or at disadvantage when it comes to carcinogenesis and success of anticancer treatments? The answer is complex, to say at least. Accumulation of unrepaired DNA damage in a cell with innate capacity for repair somewhat lower than what is considered normal (for the cell type, for the age group, for the species, etc.) may cause premature senescence of the cell and/or its elimination via the apoptosis pathway; or may trigger neoplastic transformation. Once cancer has settled in, however, and anticancer therapy has been started, it is likely that cancer cells with normal capacity for repair of DNA damage would repair the lesions induced by the genotoxic agents of chemo-and radiotherapy more effectively than cells with lower capacity for repair. In practical terms, this translates to lower risk for treatment failures and for development of resistance to various anticancer agents in cancer cells with low repair capacity. It has already been shown for different types of tumours (hematological as well as solid) that carriership of allelic forms of DNA polymorphisms associated with lower capacity for DNA repair (specifically XPD polymorphisms in exon 10 and exon 23 , as well as polymorphisms in several genes participating in repair by BER and recombination) may predict higher rates of response to treatment and better outcomes in terms of progression-free survival $(37,40,56)$. Interestingly, there are exceptions to this, as it has been shown that the presence of the Gln allele of the Lys751Gln polymorphism of the $X P D$ gene may actually be associated with reduced survival in patients treated with combined platinum/5-fluorouracil regimens for advanced colorectal cancer (52).

Lower capacity for repair of therapy-associated genotoxic damage may also mean that collateral genotoxic damage to healthy tissues following anticancer therapy may be more extensive and may be repaired less effectively. Carriership of polymorphisms in the XPD, ERCC1 and XRCC1 genes conferring lower capacity for DNA repair has been shown to be associated with higher risk for acute and late toxicity in 'standard' chemotherapy or radiotherapy regimens (40, 59). What is more, polymorphic variants of genes which are not known to be associated with substantial decrease in the capacity for DNA repair may apparently also modify the risk for toxicity following anticancer therapy, as the $R$ allele of the P72R polymorphism has been found to be more frequent in vascular skin lesions following radiotherapy for breast cancer than the $P$ allele (61). With the variety of compounds with antitumour properties constantly increasing, it could be expected that the predictive value of polymorphisms in genes related to DNA repair and maintenance of genome integrity will become an even more important factor in personalization of anticancer therapies.

\section{Usefulness of predictive testing for polymorphisms in DNA repair genes - possible ethical considerations}

What's the use of worrying? It's never been worthwhile... Pack Up Your Troubles in Your Old Kit-Bag, World War I marching song (1915)

Predictive testing for conditions with genetic bases has always been a hotspot of dispute and decisions for undertaking any genetic testing procedures are generally considered to be strictly a matter of personal choice. When it comes to testing for multiple conditions which are, by any definition, very common and may (or may not) have severe, lifelong consequences, taking the burden of responsibility of knowing that one may develop one condition or another and especially that one may pass it to its offspring becomes much more than a matter of individual 
preference. Since cancer, insulin resistance, atherosclerosis, etc. are, by general convention, multifactorial diseases, it is important that prior to any predictive testing the individual is aware that the ensuing genetic findings are not the sole cause for any condition or disease they may develop in the future. This may bring about several serious issues, mainly related to difficulties in evaluation of the biological and statistical sense of the test result. For example, a proven homozygous carrier of the $P$ allele of p53 alleles may learn and understand that this is associated with an increase in the risk of cancer in comparison to the $R$ allele carries, but they might not be able to evaluate overall cancer prevalence estimates by age group and the proportion of $\mathrm{R}$ allele carriers in the particular population so as to know whether this increase in the risk is significant or not. Similarly, carriership of the XPD exon 10 or exon 23 polymorphisms or the XPC $83 \mathrm{bp}$ insertion polymorphism in the homozygous state may increase the baseline risk for several types of cancer (for example, lung and skin cancer), but in individuals who are recreationally or professionally exposed to environmental risk factors (smoke/fumes and UV, respectively), this increase could be expected to be much larger, and it would be virtually impossible to distinguish the risk conferred by the carriership of the genetic factor alone and the risk related to the environmental hazard in the particular individual. Therefore, instead of testing for separate factors with genetic bases whose importance may be difficult to evaluate, one may instead prefer general assessment of global repair capacity in primary cell cultures $(11,13,34,39)$ which would produce an overall estimate of the capacity for repair as a function of the genotype/phenotype interaction combined with testing for phenotypic markers of the rate of cellular aging, such as rate of attrition of telomere length measured in peripheral leucocytes $(28,29)$. Still, as this carries some predictive value, one may decline any type of direct testing and choose lifestyle modifications such as quitting smoking, use of pre-irradiation and post-irradiation anti-UV measures $(9,70)$, etc. Knowledge about carriership of specific allelic forms, however, may prove very useful in individuals in which certain conditions have already occurred, such as in individuals with insulin resistance already settled in, patients with known vascular pathology, and patients eligible for certain types of therapy in which the outcome may be modified by variance in the capacity for DNA repair (genotoxic therapy for various cancers).

\section{Acknowledgements}

The authors would like to thank Northwood charitable trust for their financial support.

\section{REFERENCES}

1. Almeida A. (2012) Cell Mol. Life Sci., 2012 Jun 14. (Epub ahead of print)

2. Angelova A., Chakarov St., Tencheva Z. (1998) Comptes Rendus de l'Academie bulgare des Sciences, 51(5/6), 91-92.

3. Ara S., Lee P. S. Y., Hansen M. F., Saya H. (1990) Nucleic Acids Res., 18(16), 4961.
4. Baynes J.W. (1991) Diabetes, 40(4), 405-412.

5. Beerman I., Maloney W.J., Weissmann I.L., Rossi D.J. (2010) Curr. Opin. Immunol., 22(4), 500-506.

6. Bojesen S.E., Nordestgaard B.G. (2008) Cell Cycle, 7(2), 158-163.

7. Broughton B.C., Steingrimsdottir H., Lehmann A.R. (1996) Mutat. Res., 362, 209-211.

8. Burgdorf K.S., Grarup N., Justesen J.M., Harder M.N., et al. (2011) PLoS One, 6(1), e15813.

9. Chakarov S., Petkova R., Russev G.Ch. (2008) Biotechnol. Biotech. Eq., 22(4), 1011-1012.

10. Chakarov S., Petkova R., Russev G.Ch. (2012) Biotechnol. Biotech. Eq., 26(1), 2695-2702.

11. Chakarov S., Roeva I., Russev G. (2011) Biotechnol. Biotech. Eq., 25(3), 2505-2507.

12. Chakarov S., Russev G. (2010) Biotechnol. Biotech. Eq., 24(2), 1804-1806.

13. Chakarov St., Stoilov P., Alexandrov A, Russev G. (1997) Eur. J. Biochem., 248, 669-675.

14. Chicheva Z., Chelenkova P., Petkova R., Chakarov S. (2012) Biotechnol. Biotech. Eq., 26(4), 3142-3147.

15. Chiefari E., Tanyolaç S., Paonessa F., Pullinger C.R., et al. (2011) JAMA-J. Am. Med. Assoc., 305(9), 903-912.

16. Cleaver J.E. (1968) Nature, 218(5142), 652-656.

17. Donehower L.A. (2005) Exp. Gerontol., 40(1-2), 7-9.

18. Dumble M., Moore L., Chambers S.M., Geiger H., Van Zant G., Goodell M.A., Donehower L.A. (2007) Blood, 109(4), 1736-1742.

19. Durik M., Kavousi M., van der Pluijm I., Isaacs A., et al. (2012) Circulation, 2012 Jun 15. (Epub ahead of print)

20. Feng Z., Zhang C., Kang H.J., Sun Y., Wang H., Naqvi A., Frank A.K., Rosenwaks Z., Murphy M.E., Levine A.J., Hu W. (2011) FASEB J., 25(7), 2245-2255.

21. Foti D., Chiefari E., Fedele M., Iuliano R., Brunetti L., Paonessa F., Manfioletti G., Barbetti F., Brunetti A., Croce C.M., Fusco A., Brunetti A. (2005) Nat. Med., 11(7), 765-773.

22. Frisard M., Ravussin E. (2006) Endocrine, 29(1), 27-32.

23. Fujiwara Y., Ichihashi M., Kano Y., Goto K., Shimizu K. (1981) J. Invest. Derm., 77, 256-263.

24. Gannon H.S., Donehower L.A., Lyle S., Jones S.N. (2011) Dev. Biol., 353(1), 1-9.

25. Gomez-Sanchez J.C., Delgado-Esteban M., RodriguezHernandez I., Sobrino T., et al. (2011) J. Exp. Med., 208(3), 429-437.

26. Goekkurt E., Al-Batran S.E., Hartmann J.T., Mogck U., Schuch G., Kramer M., Jaeger E., Bokemeyer C., Ehninger G., Stoehlmacher J. (2009) J. Clin. Oncol., 27(17), 2863-2873.

27. Han J., Cox D.G., Colditz G.A., Hunter D.J. (2006) Mol. Carcinog., 45(9), 694-700.

28. Han J., Qureshi A.A., Prescott J., Guo Q., Ye L., Hunter D.J., De Vivo I. (2009) J. Invest. Dermatol., 129(2), 415-421. 
29. Hoffmann J., Spyridopoulos I. (2011) Future Cardiol., 7(6), 789-803.

30. Horibata K., Iwamoto Y., Kuraoka I., Jaspers N.G., Kurimasa A., Oshimura M., Ichihashi M., Tanaka K. (2004) Proc. Natl. Acad. Sci. U.S.A., 101(43), 1541015415.

31. Hou S.M., Fält S., Angelini S., Yang K., Nyberg F., Lambert B., Hemminki K. (2002) Carcinogenesis, 23(4), 599-603.

32. Hyka-Nouspikel N., Lemonidis K., Lu W.T., Nouspikel T. (2011) Blood, 117(23), 6277-6286.

33. Itoh T., Yamaizumi M., Ichihashi M., Hirooka M., Matsui T., Matsuno M., Ono T. (1996) Brit. J. Derm., 134, 1147-1150.

34. Kelly C.M., Latimer J.J. (2005) Methods Mol. Biol., 291, 303-320.

35. Khalil H.S., Petkova R., Zhelev N. (2012) Biotechnol. Biotech. Eq., 26(1), 2703-2711.

36. Khan S.G., Metter E.J., Tarone R.E., Bohr V.A., et al. (2000) Carcinogenesis, 21(10), 1821-1825.

37. Kuptsova-Clarkson N., Ambrosone C.B., Weiss J., Baer M.R., Sucheston L.E., et al. (2010) Int. J. Mol. Epidemiol. Genet., 1(4), 278-294.

38. Lehmann A.R. (2001) Genes Dev., 15(1), 15-23.

39. Li W., Choy D.F., Post J.M., Sullivan M.E. (2008) J. Pharmacol. Toxicol. Methods, 57(3), 220-226.

40. Ludovini V., Floriani I., Pistola L., Minotti V., et al. (2011) J. Thorac. Oncol., 6(12), 2018-2026.

41. Lunn R.M., Helzlsouer K.J., Parshad R., Umbach D.M., Harris E.L., Sanford K.K., Bell D.A. (2000) Carcinogenesis, 21(4), 551-555.

42. Madamanchi N.R., Zhou R.H., Vendrov A.E., Niu X.L., Runge M.S. (2010) Circ. Res., 107(8), 940-942.

43. Malini E., Maurizio E., Bembich S., Sgarra R., Edomi P., Manfioletti G. (2011) Biochemistry, 50(17), 3462-3468.

44. Mandal R.K., Gangwar R., Mandhani A., Mittal R.D. (2010) DNA Cell Biol., 29(4), 183-190.

45. McCormick J.J., Maher V.M. (2011) Adv. Exp. Med. Biol, 720, 191-207.

46. Mercer J.R., Cheng K.K., Figg N., Gorenne I., et al. (2010) Circ. Res., 107, 1021-1031.

47. Nahi H., Selivanova G., Lehmann S., Möllgård L., et al. (2008) Br. J. Haematol., 141(4), 445-453.

48. Nelson H.H., Kelsey K.T., Mott L.A., Karagas M.R. (2002) Cancer Res., 62(1), 152-155.

49. Nouspikel T., Hanawalt P.C. (2000) Mol. Cell. Biol., 20(5), 1562-1570.

50. Olivier M., Hollstein M., Hainaut P. (2010) Cold Spring Harb. Perspect. Biol., 2(1), a001008.

51. Padma G., Mamata M., Reddy K.R., Padma T. (2011) Mol. Vis., 17, 127-133.

52. Park D.J., Stoehlmacher J., Zhang W., Tsao-Wei D.D., Groshen S., Lenz H.J. (2001) Cancer Res., 61(24), 8654-8658.
53. Petitjean A., Mathe E., Kato S., Ishioka C., Tavtigian S.V., Hainaut P., Olivier M. (2007) Hum. Mutat., 28(6), 622-9.

54. Petkova R., Tummala H., Zhelev N. (2011) Biotechnol. Biotech. Eq., 25(4), 2572-2575.

55. Qu L., He B., Pan Y., Xu Y., Zhu C., Tang Z., Bao Q., Tian F., Wang S. (2011) Diabetes Res. Clin. Pract., 91(2), 171-176.

56. Ren S., Zhou S., Wu F., Zhang L., Li X., Zhang J., Xu J., Lv M., Zhang J., Zhou C. (2012) Lung Cancer, 75(1), 102-109.

57. Rodier F., Campisi J., Bhaumik D. (2007) Nucleic Acids Res., 35(22), 7475-7484.

58. Roy L.M., Jaruga P., Wood T.G., McCullough A.K., Dizdaroglu M., Lloyd R.S. (2007) J. Biol. Chem., 282(21), 15790-15798.

59. Sakano S., Hinoda Y., Sasaki M., Wada T., et al. (2010) Pharmacogenomics, 11(10), 1377-1387.

60. Sakoda L.C., Loomis M.M., Doherty J.A., Julianto L., et al. (2012) Int. J. Mol. Epidemiol. Genet., 3(1), 1-17.

61. Santi R., Cetica V., Franchi A., Pepi M., et al. (2011) Histopathology, 58(3), 455-466.

62. Schildkraut J.M., Goode E.L., Clyde M.A., Iversen E.S., et al. (2009) Cancer Res., 69(6), 2349-2357.

63. Seker H., Butkiewicz D., Bowman E.D., Rusin M., Hedayati M., Grossman L., Harris C.C. (2001) Cancer Res, 61(20), 7430-7434.

64. Sergentanis T.N., Economopoulos K.P. (2010) Cancer, 116(14), 3523.

65. Shen M. R., Jones I. M., Mohrenweiser H. (1998) Cancer Res., 58, 604-608.

66. Stoehlmacher J., Park D.J., Zhang W., Yang D., Groshen S., Zahedy S., Lenz H.J. (2004) Br. J. Cancer, 91(2), 344-354.

67. Sturgis E.M., Dahlstrom K.R., Spitz M.R., Wei Q. (2002) Arch. Otolaryngol. Head Neck Surg., 128(9), 10841088.

68. Sung P., Bailly V., Weber C., Thompson L.H., Prakash L., Prakash S. (1993) Nature, 365, 852-855.

69. Thomas M., Kalita A., Labrecque S., Pim D., Banks L., Matlashewski G. (1999) Molec. Cell Biol., 19, 1092-1100.

70. Tummala H., Khalil H.S., Zhelev N. (2011) Biotechnol. Biotech. Eq., 25(3), 2443-2446.

71. Unal M., Güven M., Batar B., Ozaydin A., Sarici A., Devranoğlu K. (2007) Exp. Eye Res., 85(3), 328-334.

72. Ungewitter E., Scrable H. (2009) Mech. Ageing Dev., 130(1-2), 10-17.

73. Vartanian V., Lowell B., Minko I.G., Wood T.G., Ceci J.D., George S., Ballinger S.W., Corless C.L., McCullough A.K., Lloyd R.S. (2006) Proc. Natl. Acad. Sci. U.S.A., 103(6), 1864-1869. 